\title{
Metastable phase equilibria in the ice II stability field. A Raman study of synthetic high-
} density water inclusions in quartz

\author{
Krüger, Yves; Mercury, Lionel ; Canizarès, Aurélien; Marti, Dominik; Simon, Patrick
}

Published in:

Physical Chemistry Chemical Physics

Link to article, DOI:

10.1039/C9CP03647D

Publication date:

2019

Document Version

Peer reviewed version

Link back to DTU Orbit

Citation (APA):

Krüger, Y., Mercury, L., Canizarès, A., Marti, D., \& Simon, P. (2019). Metastable phase equilibria in the ice II stability field. A Raman study of synthetic high-density water inclusions in quartz. Physical Chemistry Chemical Physics, 21(35), 19554-19566. https://doi.org/10.1039/C9CP03647D

\section{General rights}

Copyright and moral rights for the publications made accessible in the public portal are retained by the authors and/or other copyright owners and it is a condition of accessing publications that users recognise and abide by the legal requirements associated with these rights.

- Users may download and print one copy of any publication from the public portal for the purpose of private study or research.

- You may not further distribute the material or use it for any profit-making activity or commercial gain

- You may freely distribute the URL identifying the publication in the public portal 

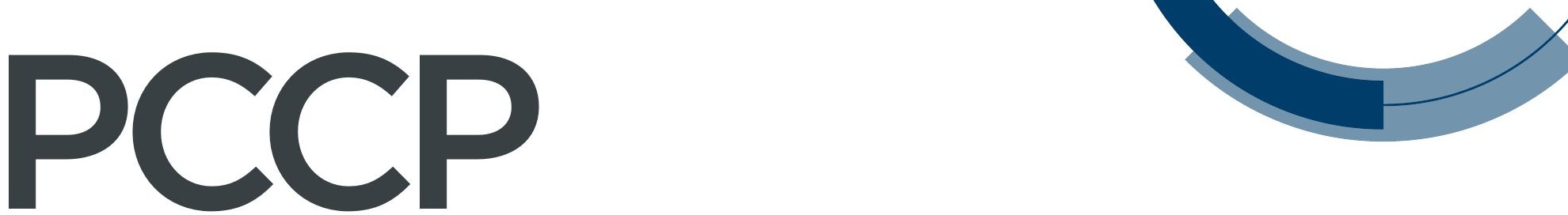

Physical Chemistry Chemical Physics

\section{Accepted Manuscript}

This article can be cited before page numbers have been issued, to do this please use: Y. Krüger, L. Mercury, A. Canizares, D. Marti and P. Simon, Phys. Chem. Chem. Phys., 2019, DOI:

\subsection{9/C9CP03647D.}
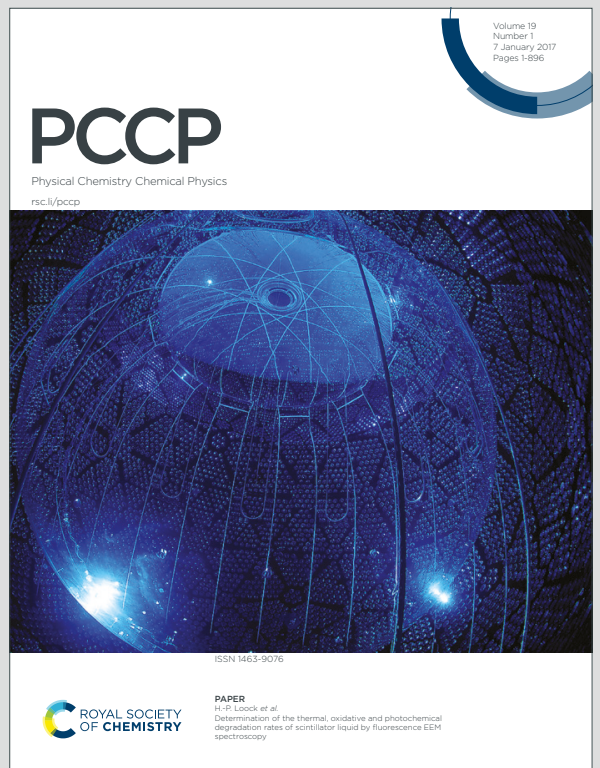

This is an Accepted Manuscript, which has been through the Royal Society of Chemistry peer review process and has been accepted for publication.

Accepted Manuscripts are published online shortly after acceptance, before technical editing, formatting and proof reading. Using this free service, authors can make their results available to the community, in citable form, before we publish the edited article. We will replace this Accepted Manuscript with the edited and formatted Advance Article as soon as it is available.

You can find more information about Accepted Manuscripts in the Information for Authors.

Please note that technical editing may introduce minor changes to the text and/or graphics, which may alter content. The journal's standard Terms \& Conditions and the Ethical guidelines still apply. In no event shall the Royal Society of Chemistry be held responsible for any errors or omissions in this Accepted Manuscript or any consequences arising from the use of any information it contains. 
Received 00th January 20xx, Accepted 00th January 20xx

DOI: $10.1039 / x 0 x \times 00000 x$

\section{Metastable phase equilibria in the ice II stability field. A Raman study of synthetic high-density water inclusions in quartz}

Yves Krüger ${ }^{\mathrm{a}, \mathrm{d}^{*}}$, Lionel Mercury ${ }^{\mathrm{a}}$, Aurélien Canizarès ${ }^{\mathrm{b}}$, Dominik Marti $^{\mathrm{c}}$, and Patrick Simon ${ }^{\mathrm{b}}$

Microthermometric measurements of a synthetic high-density $\left(984 \mathrm{~kg} / \mathrm{m}^{3}\right)$ water inclusion in quartz revealed that only part of the super-cooled liquid water $(L)$ transforms to solid ice $I_{h}$ upon ice nucleation $\left(L \rightarrow\right.$ ice $I_{h}+L$ ). While ice nucleation occurs in the ice $\ln$ stability field at $-41^{\circ} \mathrm{C}$ and $28 \mathrm{MPa}$ the pressure increases instantaneously to $315 \mathrm{MPa}$ into the ice II stability field. At this point, both phases, liquid water and ice $I_{h}$ are metastable. The coexistence of these two phases was confirmed by Raman spectroscopy and could be traced down to $-80^{\circ} \mathrm{C}$. The pressure along this low-temperature metastable extension of the ice $\ln$ melting curve was determined by means of the frequency shift of the ice $\mathrm{I}_{h}$ peak position using both the $\mathrm{O}-\mathrm{H}$ stretching band around $3100 \mathrm{~cm}^{-1}$ and the lattice translational band around $220 \mathrm{~cm}^{-1}$. At $-80^{\circ} \mathrm{C}$ and $466 \mathrm{MPa}$ the super-cooled ice $\mathrm{Ih}_{\mathrm{h}}$ melting curve encounters the homogeneous nucleation limit $\left(T_{H}\right)$ and the remaining liquid water transformed either to metastable ice IV (ice $\mathrm{l}_{\mathrm{h}}+\mathrm{L} \rightarrow$ ice $\mathrm{Ih}_{\mathrm{h}}+$ ice IV) or occasionally to metastable ice III (ice $\mathrm{I}_{\mathrm{h}}+\mathrm{L} \rightarrow$ ice $\mathrm{I}_{\mathrm{h}}+$ ice III). The nucleation of ice IV resulted in a pressure drop of about $180 \mathrm{MPa}$. Upon subsequent heating the pressure develops along a slightly negatively sloped ice $\mathrm{I}_{\mathrm{h}}$-ice IV equilibrium line terminating in a triple point at $-32.7^{\circ} \mathrm{C}$ and $273 \mathrm{MPa}$, where ice IV melts to liquid water (ice $I_{h}+$ ice IV $\rightarrow$ ice $I_{h}+L$ ). Hitherto existing experimental data of the ice IV melting curve (ice IV $\rightarrow \mathrm{L}$ ) were found to be in line with the observed ice $\mathrm{Ih}$-ice IV-liquid triple point.

If, on the other hand, ice III nucleated at $-80^{\circ} \mathrm{C}$ (instead of ice IV) the associated pressure drop was about $260 \mathrm{MPa}$. The ice $\mathrm{I}_{\mathrm{h}}$-ice III-liquid triple point was determined at $-22.0^{\circ} \mathrm{C}$ and $207 \mathrm{MPa}$ (ice $\mathrm{I}_{\mathrm{h}}+$ ice III $\rightarrow$ ice $\mathrm{I}_{\mathrm{h}}+\mathrm{L}$ ), which is in agreement with previous experimental data.

\section{Introduction}

The phase diagram of water ices is a fascinating topic of research because of the multitude of ice polymorphs with a corresponding multitude of equilibrium curves and triple points ( $c f$. reviews $1,2,3$, and references therein). About 19 crystalline ice polymorphs (ice I ( $h$ and c) - ice XVIII) and three amorphous ice phases (LDA, HDA, VHDA) have been identified so far. Owing to the large number of ice polymorphs and extensive metastability of these phases outside their range of stability (e.g. Bridgman ${ }^{4}$, p. 530-533), the phase diagram of solid water is fairly complex. Moreover, two of the ice polymorphs, ice IV and ice XII, exist only in metastable form within the stability fields of other ice phases. Based on the ordering state of the hydrogen atoms, the crystalline ices can be assigned to two structural groups featuring hydrogen-disordered (ices $I_{h}$, III, IV, V, $\mathrm{VI}, \mathrm{VII}$ and XII, XVI, XVII) or hydrogen-ordered structures (ices II, VIII, $I X, X I, X I I I, X I V, X V)$ ). Ices with hydrogen-disordered structures have all in common that they share a stable or metastable (ices IV and XII) phase boundary with liquid water. Extensions of these ice melting curves beyond their stability ranges into metastable domains are common and have been reported for several ice 
phases..$^{5-9}$ Furthermore, it is also known that liquid water can be super-cooled below its freezing temperature by up to $70^{\circ} \mathrm{C},{ }^{10}$ and the ice phases that eventually form upon freezing always exhibit hydrogen-disordered structures.

Experimental investigations of the ice phase diagram are typically performed in pressure cells in order to produce the high-pressure ice phases to be investigated (e.g. refs. ${ }^{4,5,9-11}$ ). The occurrence of phase transitions (crystallisation or melting) induced by pressure and temperature changes are recorded by means of differential thermal analyses and/or by volume changes of the ice/water sample. The technique is relatively simple and allows full control of temperature, pressure and volume. Fluid inclusions, in contrast, are closed microscopic systems in a crystal, in which the pressure changes as a function of temperature and density (isochores), and hence is not an independent variable of the experiment. The optical transparency of the host crystal, however, allows for direct visual observations of phase transitions and in-situ identification of the phases by Raman spectroscopy. In previous experimental studies synthetic fluid inclusions have successfully been used to explore the metastable super-heated domain of liquid water reaching negative pressures up to $-140 \mathrm{MPa} .{ }^{12-16}$ The present study uses this experimental approach to explore metastable phase equilibria at temperatures below ice nucleation.

Recently, an extensive experimental study has been published by Qiu et al. ${ }^{16}$ exploring the low-temperature metastable region of liquid water using synthetic fluid inclusions in quartz. By means of classical fluid inclusion microthermometry they measured temperatures $(T)$ of a series of different phase transitions as a function of density $(\varrho)$ in the temperature range between 150 and $-4{ }^{\circ} \mathrm{C}$ determining the $\varrho-T$ trends of 1 . the ice nucleation curve at negative pressures, 2 . the ice $I_{h}$ melting curve at negative pressures, 3. the super-cooled saturation curve, and 4 . the line of spontaneous vapour bubble nucleation (cavitation) at high negative pressures.

The present study ties in with the work of Qiu et al. by extending it to temperatures below ice nucleation.

The nucleation of ordinary ice $I_{h}$ in (nearly) isochoric systems like fluid inclusions forcibly results in an intense increase of pressure due to the larger volume of ice compared to liquid water. For highdensity inclusions it is thus expected that the pressure increases well above $200 \mathrm{MPa}$ upon ice nucleation, transferring the system into the ice II stability field ( $c f$. ref. ${ }^{4}$ ). In consideration of such high pressures it was surprising to see that irreversible volume changes of the inclusions due to brittle and/or plastic deformation were very small, indicated by only slight increases of subsequently remeasured liquid-vapour homogenisation temperatures $\left(T_{h}\right)$. Furthermore, it was observed that irreversible volume changes did not systematically increase with increasing water densities of the inclusions. The initial motivation for conducting this study, therefore, was to identify the ice phase(s) actually present in the inclusions after nucleation using Raman spectroscopy.

In contrast to Qiu et al. who assumed that liquid water transforms completely to solid upon ice nucleation, attentive microthermometric observations revealed that a small fraction of liquid water remains in the inclusion coexisting with ice. This finding has opened a new pathway to investigate both solid-liquid and solid-solid phase relations in the water phase diagram by means of synthetic fluid inclusions.

The Material and Methods section describes the synthetic fluid inclusion samples used for this study, the experimental setup, and the Raman measurements. We then report on the results of the microthermometric and Raman spectroscopic measurements, on a new calibration to quantify the shift of the ice $I_{h}$ Raman bands as a function of temperature and pressure, and we present a $p-T$ phase diagram. The results will then be discussed and compared to available literature data.

\section{Materials and Methods}

\section{Fluid inclusion samples}

For the present study we used new thick-sections cut from the same synthetic fluid inclusion samples that had been used by Qiu et al. ${ }^{16}$ The synthetic fluid inclusions were produced in sealed gold capsules containing only deionised (air-saturated) water and prefractured inclusion-free natural quartz that was cut to prisms perpendicular to the quartz c-axis. No additives like silica gel or $\mathrm{NaOH}$ were used to enhance quartz solubility during hydrothermal synthesis and no excess air was trapped in the sealed capsules. Hydrothermal syntheses were performed in an internally heated pressure vessel in the HP-GeoMatS Laboratory at GFZ Potsdam. For our study we selected a high-density $\left(984 \mathrm{~kg} / \mathrm{m}^{3}\right)$ fluid inclusion with a size of approximately $120 \mu \mathrm{m}^{3}$ (inclusion A, sample MW15). Synthesis conditions of sample MW15 were at $460^{\circ} \mathrm{C}$ and $860 \mathrm{MPa}$ for a run duration of 54 hours. After hydrothermal synthesis, the quartz prism, now containing numerous fluid inclusions along the healed fractures, was cut to sections of approximately $300 \mu \mathrm{m}$ thickness with the cut face approximately parallel to the quartz caxis. The sections were then polished on both sides to make them transparent for microscopic observation of the fluid inclusions in transmitted light. For a detailed description of the synthesis procedure and sample preparation we refer to Qiu et al. ${ }^{16}$ (Supplementary Material).

Inclusion A selected for this study is in a metastable liquid state at room temperature. Single ultra-short laser pulses were used to stimulate vapour bubble nucleation ${ }^{17}$, thus transferring the inclusion from a metastable liquid to a stable liquid-vapour twophase state. Subsequently, the density of the encapsulated water and the volume of the inclusion were determined based on the measured liquid-vapour homogenisation temperature $T_{h}(L+V a p \rightarrow$ $\mathrm{L}$ ) and on the vapour bubble radius $r(T)$ using a thermodynamic model that accounts for the effect of surface tension on liquidvapour homogenisation. ${ }^{18}$

A second, low-density synthetic water inclusion (B) with $\varrho=826$ $\mathrm{kg} / \mathrm{m}^{3}$ and a volume of about $2700 \mu \mathrm{m}^{3}$, was used to determine the temperature-dependent shift $(\partial v / \partial T)_{p=0}$ of the ice $I_{h}$ Raman bands around $3100 \mathrm{~cm}^{-1}\left(\mathrm{O}-\mathrm{H}\right.$ stretching mode) and at $220 \mathrm{~cm}^{-1}$ (lattice translational mode) along the water sublimation curve, i.e., virtually at zero pressure. Due to its low density inclusion $B$ is in a stable 
liquid-vapour two-phase state at room temperature, and consequently, the pressure follows along the saturation curve upon cooling until ice nucleation occurs ( $L+V a p \rightarrow$ ice $\left.I_{h}+V a p\right)$. There, the pressure drops from saturation to sublimation pressure and the vapour bubble becomes slightly compressed due to the larger volume of ice $I_{h}$ compared to liquid water. Ice melting (ice $I_{h}+V a p$ $\rightarrow \mathrm{L}+\mathrm{Vap}$ ) was observed at $0.0^{\circ} \mathrm{C}$, showing the characteristic feature of the triple point transition, namely the instantaneous melting of all the ice within $0.1^{\circ} \mathrm{C}$.

\section{Experimental setup}

Microthermometic measurements were performed using a Linkam THMS 600 heating/cooling stage mounted on an Olympus BX-41 upright microscope. The microscope was equipped with an Olympus LMPlanFL 100x/0.8 long-working distance objective for visual observation of the inclusions during microthermometric measurements. Temperature calibrations of the heating/cooling stage were performed using synthetic $\mathrm{H}_{2} \mathrm{O}$ and $\mathrm{H}_{2} \mathrm{O}-\mathrm{CO}_{2}$ fluid inclusion standards. The reference temperatures measured were the triple point of water $\left(0.0^{\circ} \mathrm{C}\right)$ and the triple point of $\mathrm{CO}_{2}(-56.6$ $\left.{ }^{\circ} \mathrm{C}\right)$. The temperature accuracy of our measurements is estimated at $\pm 0.1{ }^{\circ} \mathrm{C}$ around $0{ }^{\circ} \mathrm{C}$ and at $\pm 0.2^{\circ} \mathrm{C}$ below $-40{ }^{\circ} \mathrm{C}$, while precision (reproducibility) was $\pm 0.05^{\circ} \mathrm{C}$.

The microscope with the heating/cooling stage was attached to a T64000 triple spectrometer (Horiba) equipped with a backilluminated, liquid nitrogen cooled CCD detector with $26 \mu \mathrm{m} \times 26$ $\mu \mathrm{m}$ pixel size (SYMPHONY, Horiba). Calibration of the spectrometer was accomplished by means of the $521 \mathrm{~cm}^{-1}$ Raman peak of a silicon standard. In triple subtractive spectrometer configuration (three 1800 grooves/mm gratings) the setup allows the acquisition of Raman spectra in the low-frequency range as low as $10 \mathrm{~cm}^{-1}$, though at the cost of signal intensity. For higher frequencies, a single spectrometer configuration was used (one 1800 grooves $/ \mathrm{mm}$ grating and edge filter). A $514.5 \mathrm{~nm}$ argon-krypton laser (Coherent Innova $70 \mathrm{C}$ ) was used for Raman excitation. While the nominal output power of the laser is $300 \mathrm{~mW}$, the effective laser power on the sample was about $20 \mathrm{~mW}$ and thus low enough to avoid any measurable heating of the fluid inclusions. This was confirmed by the reproducibility of ice melting temperatures measured with and without laser irradiation of the sample. The spectral resolution of the system is $0.66 \mathrm{~cm}^{-1}$ at $220 \mathrm{~cm}^{-1}$ and $0.42 \mathrm{~cm}^{-1}$ at $3100 \mathrm{~cm}^{-1}$. Raman measurements were performed in back-scattering geometry using the Olympus LMPlanFL 100x/0.8 objective for focussing the laser beam into the sample and for collecting the Raman- and Rayleigh-scattered light. The setup was designed for polarisationdependent Raman measurements featuring a rotatable half-wave plate in the excitation light path and a fixed, vertically oriented polariser in the light path of the back-scattered Raman signal.

\section{Raman measurements}

Raman spectroscopy was used in this study to identify different phases occurring during the microthermometric runs and to determine the pressure in the inclusion based on the shift of the ice Ih peak position.
Low-frequency Raman spectra were obtained in triple spectrometer configuration at temperatures between -0.4 and $-80^{\circ} \mathrm{C}$. Using the 1800 grooves $/ \mathrm{mm}$ gratings the spectral window ranges from 14 to $670 \mathrm{~cm}^{-1}$, covering the lattice translational Raman bands of the different ice polymorphs. Spectra were obtained by averaging two measurements, each with 120 seconds acquisition time to reduce the signal-to-noise ratio. The crystallographic orientation of the quartz thick section was set to extinction between crossed polarisers. Subsequently, the Raman spectra were measured in $x y$ (also denoted as $\mathrm{HV}$ ) polarisation, where $\mathrm{x}$ (or $\mathrm{H}=$ horizontal) denotes the polarisation direction of the excitation laser and $y$ (or $V$ $=$ vertical) the polarisation direction of the Raman signal measured in the spectrometer. Using this configuration, we were able to almost entirely suppress the strong $A_{1}$ Raman band of the quartz host occurring at about $206 \mathrm{~cm}^{-1}$ that superimposes the translational bands of ice $I_{h}$.

In addition to spectra of the ice phases in the inclusion, we also measured the spectra of the quartz host next to the inclusion at the same depth and temperatures and with the same acquisition time. Although the measurements were performed with a confocal setup using a $100 \mu \mathrm{m}$ pinhole the intensities of the remaining quartz peaks were only slightly lower when the laser was focussed into the inclusion. This is likely due to the small volume of inclusion A, specifically its small z-extension (about $3 \mu \mathrm{m}$ ) in axial direction of the laser focus. In comparison to this, the 20 times larger lowdensity inclusion B showed a dramatic decrease of the quartz signal when focussing into the inclusion.

In contrast to the low-frequency measurements, Raman spectra of the $\mathrm{O}-\mathrm{H}$ stretching bands were measured in single spectrometer configuration and yy $(\mathrm{HH})$ polarisation also using a 1800 grooves/mm grating. Three spectral windows were necessary to cover the frequency range from 2710 to $3890 \mathrm{~cm}^{-1}$. Acquisition time was $2 \times 30$ seconds for each window, indicating a significantly higher Raman intensity compared to the lattice translational bands. A total of 276 individual Raman spectra were measured for this study.

\section{Data treatment}

The Raman raw spectra were corrected to account for shifts of the spectrometer using the reference peak position of the silicon standard measured at room temperature, as well as the position of the two low-frequency quartz bands at about 130 and $260 \mathrm{~cm}^{-1}$ at known temperatures. The position of the dominant peak of the ice Ih $\mathrm{O}-\mathrm{H}$ stretching band was determined directly from the spectrum with an estimated precision of about $\pm 1.5 \mathrm{~cm}^{-1}$. The peak position of the lattice translational band of ice $\mathrm{I}_{\mathrm{h}}$ was determined after subtraction of the normalised quartz spectrum taken at the same 


\section{Cooling}
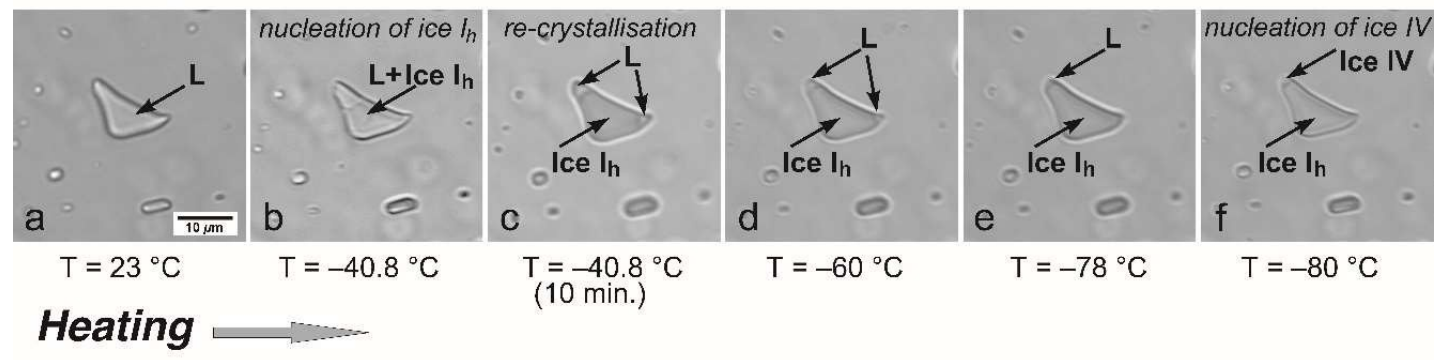

$\mathrm{T}=-78^{\circ} \mathrm{C}$

$\mathrm{T}=-80^{\circ} \mathrm{C}$
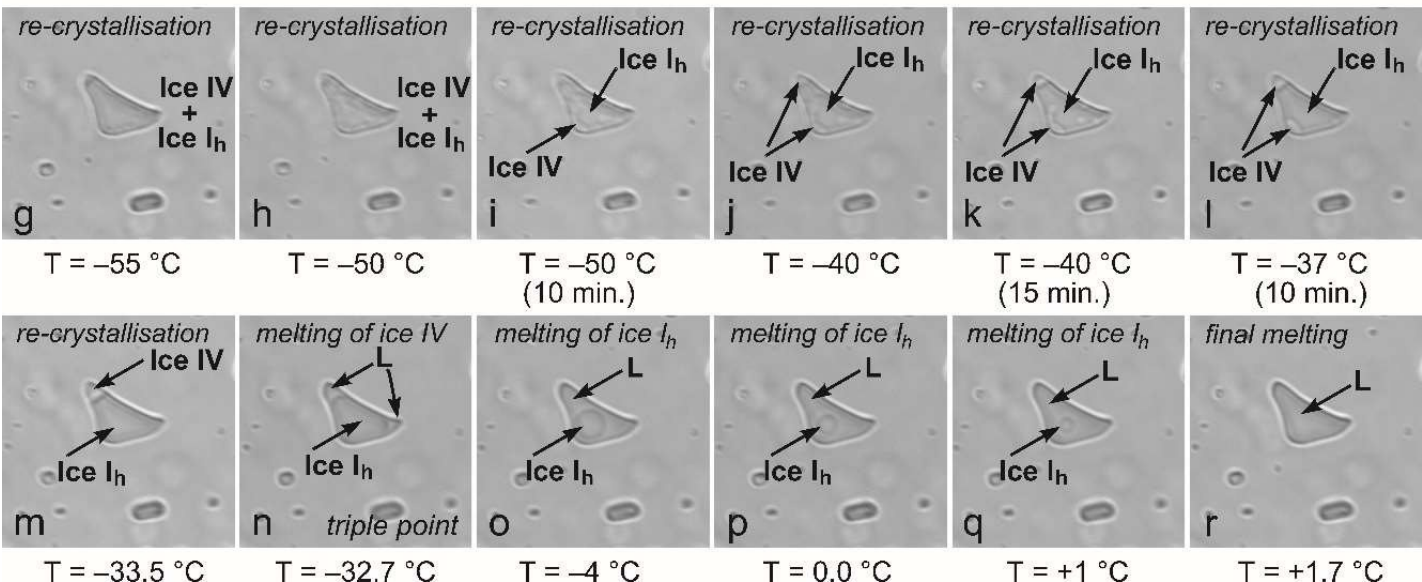

$\mathrm{T}=-50^{\circ} \mathrm{C}$
$(10 \mathrm{~min})$

$\mathrm{T}=-40^{\circ} \mathrm{C}$

$\mathrm{T}=-40^{\circ} \mathrm{C}$

$\mathrm{T}=-37^{\circ} \mathrm{C}$

melting of ice $t_{h}$

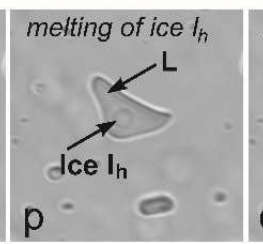

melting of ice $I$.

(10 min.)

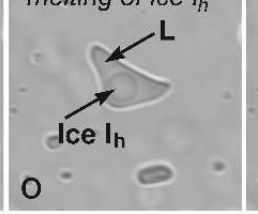

$\mathrm{T}=-4^{\circ} \mathrm{C}$

$\mathrm{T}=0.0^{\circ} \mathrm{C}$
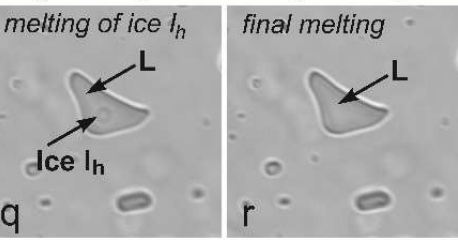

Figure 1: Series of photographs of inclusion $\mathrm{A}$ at different temperatures illustrating the phase transitions observed upon cooling and subsequent heating. A scale is indicated in image a. For a detailed description we refer to the text

temperature. Here the uncertainty of the peak determination is estimated at $\pm 0.75 \mathrm{~cm}^{-1}$.

\section{Results}

\section{Microthermometric measurements}

Figure 1 shows a sequence of photographs illustrating the phase changes observed in the high-density fluid inclusion A upon cooling (upper panel) and upon subsequent heating (lower panel). At $23^{\circ} \mathrm{C}$ (Fig. 1a) the water in the inclusion is in a metastable liquid state at negative pressure, i.e., the liquid water is under tensile stress. Upon cooling the pressure in the inclusion further decreases, following a pseudo-isochoric trajectory (see Marti et al. ${ }^{19}$ ), reaches a pressure minimum, and finally increases again to positive pressure as illustrated in Fig 2. On its re-entrant branch the liquid-isochore intersects the metastable extension of the saturation curve ( $L+V a p)$ at about $-27^{\circ} \mathrm{C}$, which is referred to as the retrograde liquid-vapour homogenisation temperature $T_{h r} .{ }^{16,19}$ Upon further cooling, the nucleation of ice $I_{h}\left(T_{n} I_{h}\right)$ was observed at about $-41^{\circ} \mathrm{C}$ (Fig $1 \mathrm{~b}$ ). Assuming that the nucleation temperature of ice $I_{h}$ is close to the homogeneous nucleation limit $T_{\mathrm{H}}$, the pressure at $T_{n} \ln _{\mathrm{h}}$ was calculated at $28 \mathrm{MPa}$ using Equation $\mathrm{A} 1$ of Holten et al. ${ }^{20}$ While ice nucleation takes place in the ice $\mathrm{I}_{\mathrm{h}}$ stability field, the pressure in the inclusion increases abruptly upon freezing. Fig. 1c demonstrates that ice $I_{h}$ does not entirely fill the inclusion volume but coexists with liquid water that has not completely transformed to solid.
Thus, the phase transition occurring at $T_{n} I_{h}$ is $\mathrm{L} \rightarrow$ ice $\mathrm{I}_{\mathrm{h}}+\mathrm{L}$. The presence of liquid water coexisting with ice $I_{h}$ was confirmed by Raman spectroscopy (see Fig. 4b) and is corroborated by the convex shape of the ice $I_{h}$ crystal boundary (Fig. 1c), which is characteristic for the liquid-solid interface. We note that the presence of liquid water promotes a rapid re-crystallisation of the initially polycrystalline ice to a single ice $\mathrm{I}_{\mathrm{h}}$ crystal (cf. Fig. $1 \mathrm{~b}$ and $1 \mathrm{c}$ ).

Upon further cooling (Fig. 1d and 1e) ice $I_{h}$ grows at the expense of the liquid phase, indicating a metastable equilibrium between the two phases. Conversely, ice $I_{h}$ melts continuously upon heating following the image sequence e-c, $n-q$ and in turn grows again upon cooling. At about $-80^{\circ} \mathrm{C}$, finally, a phase transition occurs that results in an abrupt pressure drop (see Fig. 2). Although this phase transition could not be observed directly (Fig. 1f) we observed the re-crystallisation and coalescence of a second solid phase upon subsequent heating, starting at about $-55^{\circ} \mathrm{C}$ (Fig. 1g). We found strong evidence indicating that this newly formed phase is ice IV, a metastable, hydrogen-disordered form of ice ( $c f$. Fig. 4a and Fig. $8 a, b)$. Fig. 1g-m illustrate the sluggish re-crystallisation and coalescence process of ice IV that apparently formed from the 


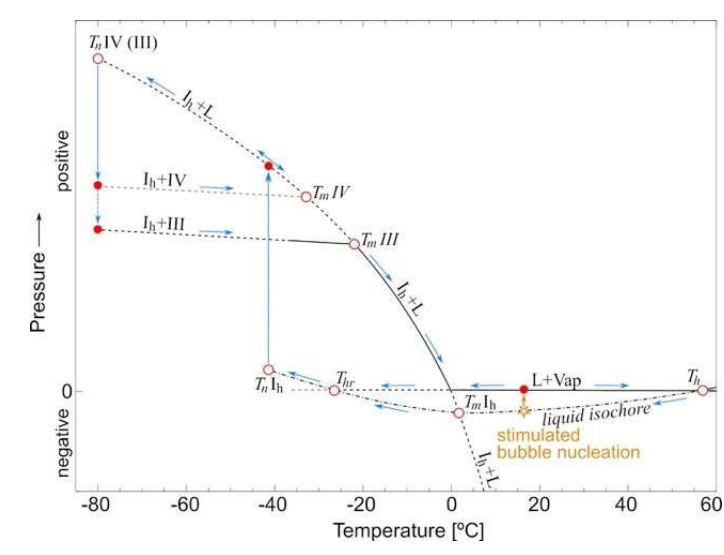

Figure 2: Schematic representation of the $p-T$ trajectories (blue arrows) of inclusion A during the microthermometric runs. L+Vap: liquid-vapour equilibrium curve; $I_{h}+L$ : ice $I_{h}$ melting curve; $I_{h}+I V$ : ice $I_{h}$-ice IV coexistence curve; $\mathrm{l}_{\mathrm{h}}+\mathrm{III}$ : ice $\mathrm{I}_{\mathrm{h}}$-ice III coexistence curve. Solid lines: stable phase states, dashed lines: metastable phase states. Below the liquid-vapour homogenisation temperature $T_{h}$ the monophase liquid state of the inclusion becomes metastable (dash-dotted isochore), first with respect to vapour, then, below $T_{m} I_{h}$ with respect to both vapour and ice $I_{h}$, and finally below $T_{h r}$ with respect to ice $\ln$ only. The orange star indicates the option to stimulate vapour bubble nucleation by means of ultra-short laser pulses, ${ }^{17}$ which allowed us to measure $T_{h}$ and $T_{h r}$, the temperatures of prograde and retrograde liquid-vapour homogenisation, respectively. $T_{n}$ and $T_{m}$ denote the nucleation and the melting temperatures of the ice phases (Ih, III or IV), respectively. See text for further details.

liquid water film between the ice $I_{h}$ crystal and the inclusion walls (ice $\mathrm{I}_{\mathrm{h}} \mathrm{L} \rightarrow$ ice $\mathrm{I}_{\mathrm{h}}+\mathrm{ice} \mathrm{IV}$ ). We assume that the re-crystallisation and coalescence of ice IV is likely caused by the Gibbs-Thomson effect, i.e., the depression of the equilibrium melting temperature as a function of the interfacial curvature of the ice crystals ${ }^{21}$ that presumably are at the nanoscale when formed at $-80^{\circ} \mathrm{C}$. The presence of an inter-crystalline liquid water film would promote recrystallisation, resulting in an increase of the crystal grain size, and consequently, in an increase of the melting temperature. At about $34{ }^{\circ} \mathrm{C}$ (Fig. $1 \mathrm{~m}$ ) the two ice phases were completely separated, featuring a nearly linear solid-solid interface between two single crystals, ice IV and ice $I_{h}$. In contrast to the ice $I_{h}$-liquid phase equilibria, the volume ratio of ice IV and ice $\mathrm{I}_{\mathrm{h}}$ does not perceivably change between -34 and $-80^{\circ} \mathrm{C}$ as illustrated in Fig. $3 a$.

At $-32.7^{\circ} \mathrm{C}$ (Fig. 1n), ice IV melts to liquid water (ice $I_{h}+$ ice IV $\rightarrow$ ice $\mathrm{I}_{\mathrm{h}}+\mathrm{L}$ ), defining a triple point that has previously been reported from experiments in a hydrothermal diamond-anvil cell. ${ }^{22}$ After melting of ice IV, the remaining ice $I_{h}$, now coexisting with liquid water, melts continuously with increasing temperature (Fig. $1 \mathrm{n}$-q) until final ice melting $\left(T_{m} I_{h}\right)$ was observed at $+1.7^{\circ} \mathrm{C}$ (Fig. 1r), indicating that the inclusion has returned to the negative pressure domain. The reproducibility of the ice IV nucleation temperature $\left(T_{n} I \mathrm{~V}\right)$ is \pm 1 ${ }^{\circ} \mathrm{C}$, whereas the precision of the triple point and the final ice melting temperature is $\pm 0.05^{\circ} \mathrm{C}$. Although our observations and microthermometric measurements have proven to be highly reproducible, there is one exception: in one of the very last microthermetric runs we performed for this study, we observed that, after cooling the inclusion to $-80^{\circ} \mathrm{C}$, ice III had formed instead of ice IV (ice $I_{h}+L \rightarrow$ ice $I_{h}+$ ice III). Initially, we supposed that the formation of ice III was caused by the higher cooling rate we had used for this specific run $(40 \% \mathrm{~min})$. However, it turned out that the formation of ice III could not be reproduced reliably and formed, if at all, rather by chance. Upon subsequent heating ice III underwent a re-crystallisation and coalescence process similar to that observed for ice IV. After separation of the two coexisting ice phases, we found the volume of ice III to be significantly larger than that of ice IV. But, similar to the ice $I_{h}$-ice IV assemblage, the ice III/ice $I_{h}$ volume ratio did not perceivably change between -24 and $-80^{\circ} \mathrm{C}$ (see Fig. 3b). The coexistence of ice III and ice $\mathrm{I}_{\mathrm{h}}$ finally terminates at $-22.0^{\circ} \mathrm{C}\left(T_{m}\right.$ III) in a triple point (ice $\mathrm{I}_{\mathrm{h}}+\mathrm{ice} \mathrm{III} \rightarrow$ ice $\mathrm{I}_{\mathrm{h}}+\mathrm{L}$ ), which is in agreement with the respective triple point temperature reported by Bridgman. ${ }^{4}$

\section{Raman spectra}

Identification of phases. The different phases occurring during the microthermometric runs were analysed by Raman spectroscopy and compared to reference spectra of different ice polymorphs reported by Minceva-Sukarova et al. ${ }^{23}$

A compilation of Raman spectra of the different phases observed in this study is shown in Fig. 4a for the low-frequency lattice translational bands and in Fig. 4b for the high-frequency $\mathrm{O}-\mathrm{H}$

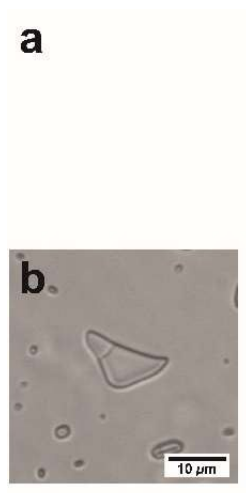

$\mathrm{T}=-24^{\circ} \mathrm{C}$
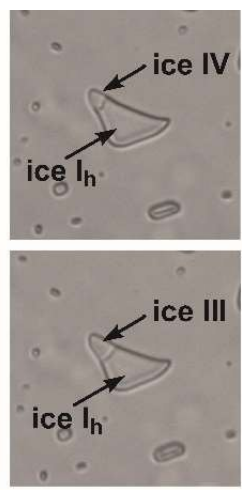

$\mathrm{T}=-35^{\circ} \mathrm{C}$
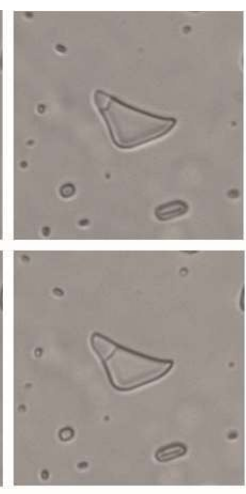

$\mathrm{T}=-60^{\circ} \mathrm{C}$
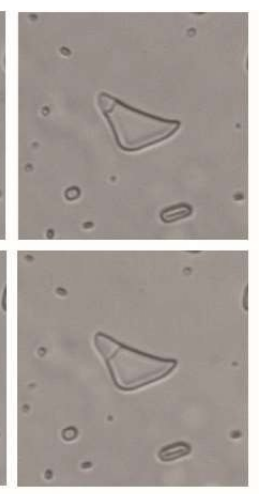

$\mathrm{T}=-80^{\circ} \mathrm{C}$

Fig. 3: Photographs illustrating a) the ice IV/ice $\ln$ and b) the ice III/ ice $\ln$ volume ratios. The volume ratios of the coexisting ice phases do not perceptibly change with temperature. 

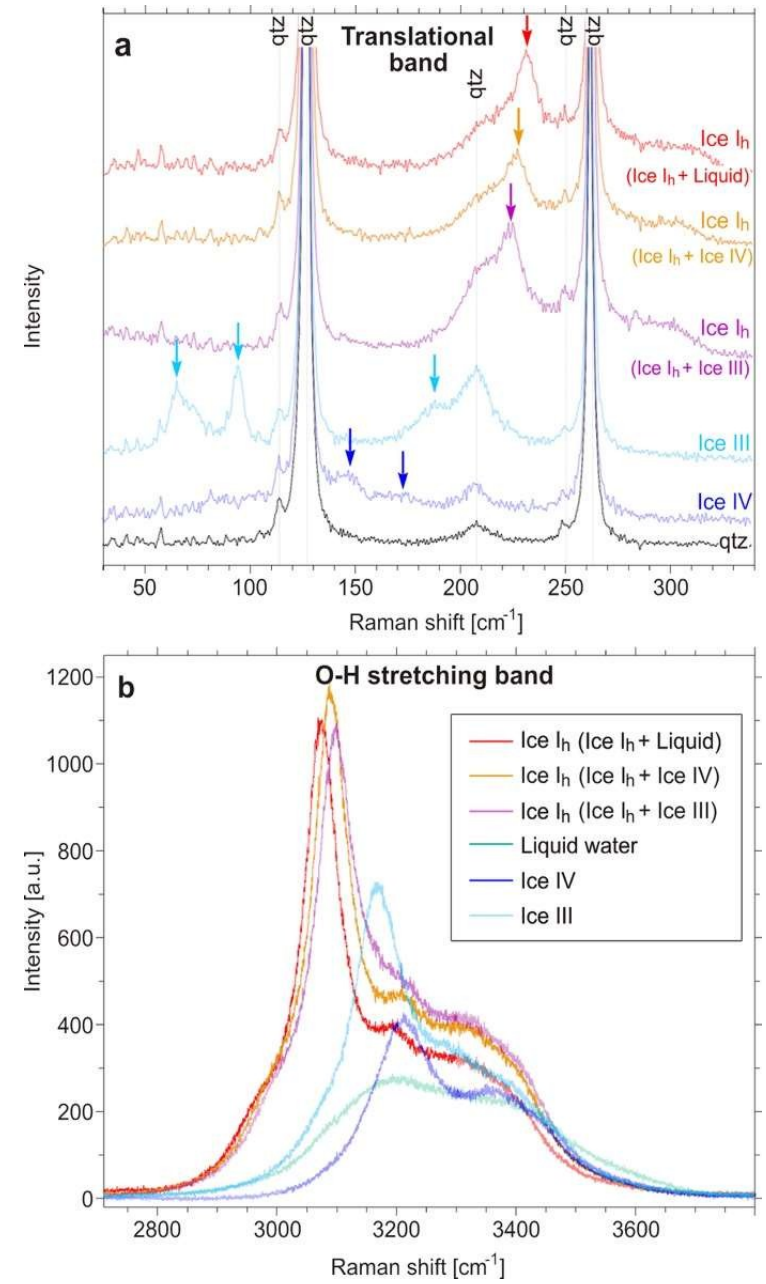

Figure 4: Raman spectra of ice $\mathrm{I}_{\mathrm{h}}$ (red, orange and purple), ice III (light blue) and ice IV (blue) measured at $-58.4^{\circ} \mathrm{C}$. The peak positions of the ice $\ln$ spectra reflect the different pressures at which ice $\mathrm{I}_{\mathrm{h}}$ coexists with liquid water, ice IV and ice III, respectively. a) Low- frequency Raman spectra of the lattice translational bands. Arrows indicate the peak positions of the respective ice phases. A quartz reference spectrum (black) measured in xy polariser configuration is shown for comparison. b) High-frequency Raman spectra of the $\mathrm{O}-\mathrm{H}$ stretching bands. The spectrum of liquid water coexisting with ice $\mathrm{I}_{\mathrm{h}}$ is depicted in turquoise.

stretching bands. The spectra were measured after complete recrystallisation and separation of the coexisting phases (ice $\mathrm{I}_{\mathrm{h}}+$ ice III, ice $I_{h}+$ ice IV and ice $I_{h}+$ liquid, respectively), which allowed us to record Raman spectra of the individual phases. All spectra shown were taken at $-58.4^{\circ} \mathrm{C}$ including the quartz reference spectrum (black) in Fig. 4a.

Ice $I_{h}$ could be clearly identified from the low-frequency spectrum with its characteristic peak at about $220 \mathrm{~cm}^{-1}$. The different spectra of ice $\mathrm{I}_{\mathrm{h}}$ shown in Fig. 4 correspond to the three different phase assemblages indicated in parentheses: ice $I_{h}+L$ (red), ice $I_{h}+i c e ~ I V$ (orange), and ice $I_{h}+$ ice III (purple). The clear shift of the ice $I_{h}$ peak position denotes that ice $\mathrm{I}_{\mathrm{h}}$ is under different pressure depending on the phase assemblage.

The identification of ice IV (blue) was more difficult because of the low intensity of the translational bands in the Raman spectrum. The only ice IV reference spectra we could find in the literature are those reported by Salzmann et al. ${ }^{24}$, which were recorded between -193 and $-133^{\circ} \mathrm{C}$ and at 1 bar pressure, and hence, at significantly different $p-T$ conditions than our measurements $\left(-58.4^{\circ} \mathrm{C}, 281\right.$ $\mathrm{MPa}$ ). Furthermore, their spectra were measured on polycrystalline samples, whereas in the present study, the spectra were taken from a single crystal of unknown crystallographic orientation. The lowfrequency spectrum of ice IV shown in Fig. 4a exhibits a weak but clear band at about $150 \mathrm{~cm}^{-1}$ and a broad, rather vague band around $170 \mathrm{~cm}^{-1}$. The two bands appear in all our ice IV spectra of the lattice translational mode and are clearly absent in the underlying quartz spectrum. For comparison, the low-frequency spectrum of Salzmann et al. recorded at $-138^{\circ} \mathrm{C}$ displays two major bands at about 150 and $175 \mathrm{~cm}^{-1}$ plus two minor bands at about 125 and $205 \mathrm{~cm}^{-1}$. While the two major bands conform quite well with those observed in our spectra, the latter two are not identifiable in our spectra because of the low signal intensity and the superposition with quartz bands. Our high-frequency spectrum of the $\mathrm{O}-\mathrm{H}$ stretching bands, on the other hand, displays two broad peaks at about 3210 and $3350 \mathrm{~cm}^{-1}$. The respective peak positions reported by Salzmann et al. ${ }^{24}$ at $-193^{\circ} \mathrm{C}$ and 1 bar are at 3200 and $3330 \mathrm{~cm}^{-1}$.

The identification of ice III (light blue) again appears quite clear, based on the distinct low-frequency Raman bands at about 65, 95, and $190 \mathrm{~cm}^{-1}$, which are qualitatively in agreement with the corresponding spectrum reported by Minceva-Sukarova et al. ${ }^{23}$ taken at $-27^{\circ} \mathrm{C}$ and $280 \mathrm{MPa}$. For comparison, the ice III spectra shown in Fig 4 were measured at $-58.4^{\circ} \mathrm{C}$ and $208 \mathrm{MPa}$. Although the spectra obtained in this study do not allow a clear discrimination between the hydrogen-disordered ice III and ice IX, its hydrogen-ordered equivalent, it is unlikely that the hydrogenordered ice polymorph formed directly by nucleation from liquid water. We note that the intensity of the $A_{1}$ quartz band $\left(206 \mathrm{~cm}^{-1}\right)$ in the ice III (light blue) and in the corresponding ice $\mathrm{I}_{\mathrm{h}}$ spectrum (lilac) is slightly higher compared to the other spectra. This is caused by a slight misalignment of the quartz orientation with respect to the Raman polarisation directions (xy configuration), which became obvious from the respective quartz reference spectrum (not shown in Fig 4a). The Raman spectrum of ice III in the O-H stretching region reported by Minceva-Sukarova et al..$^{23}$ (see their Fig. 5a) displays a sharp peak about $3150 \mathrm{~cm}^{-1}$ and a high, broad shoulder at about $3300 \mathrm{~cm}^{-1}$. In our own high-frequency spectrum (Fig. 4b), however, the intensity of the $3300 \mathrm{~cm}^{-1}$ stretching band is very low and does not form a pronounced peak.

The identification of liquid water coexisting with ice $I_{h}$ was possible only in the $\mathrm{O}-\mathrm{H}$ stretching region (turquoise curve in Fig. 4b). At low frequencies, i.e., in triple spectrometer configuration, the signal intensity was too low and only the broadening of the Rayleigh band was observed.

Ice $I_{h}$ peak positions. The broad Raman $\mathrm{O}-\mathrm{H}$ stretching band of ice $\mathrm{I}_{\mathrm{h}}$ is a superposition of 3 to 4 sub-bands with a dominant peak around $3100 \mathrm{~cm}^{-1}$ (e.g. ${ }^{25,26}$ ). The exact position of this peak depends on temperature and pressure, and shifts towards higher wave 
Table 1: Low- and high-frequency Raman peak positions of ice $\mathrm{I}_{\mathrm{h}}$ measured for four different phase assemblages as a function of temperature

\begin{tabular}{|c|c|c|c|c|c|c|c|c|}
\hline \multirow[b]{2}{*}{$\begin{array}{c}\text { Temperature } \\
{\left[{ }^{\circ} \mathrm{C}\right]}\end{array}$} & \multicolumn{4}{|c|}{ Lattice translational band } & \multicolumn{4}{|c|}{$\mathrm{O}-\mathrm{H}$ stretching band } \\
\hline & $\begin{array}{c}\text { Ice } \mathrm{Ih}_{\mathrm{h}} \\
\text { peak pos. } \\
\left(\mathrm{I}_{\mathrm{h}}+\mathrm{L}\right) \\
{\left[\mathrm{cm}^{-1}\right]}\end{array}$ & $\begin{array}{c}\text { Ice } \mathrm{Ih}_{\mathrm{h}} \\
\text { peak pos. } \\
\left(\mathrm{l}_{\mathrm{h}}+\mathrm{IV}\right) \\
{\left[\mathrm{cm}^{-1}\right]}\end{array}$ & $\begin{array}{c}\text { Ice } \mathrm{Ih}_{\mathrm{h}} \\
\text { peak pos. } \\
\left(\mathrm{I}_{\mathrm{h}}+\mathrm{III}\right) \\
{\left[\mathrm{cm}^{-1}\right]}\end{array}$ & $\begin{array}{c}\text { Ice } \mathrm{Ih}_{\mathrm{h}} \\
\text { peak pos. } \\
\left(\mathrm{I}_{\mathrm{h}}+\mathrm{Vap} .\right) \\
{\left[\mathrm{cm}^{-1}\right]}\end{array}$ & $\begin{array}{c}\text { Ice } \mathrm{Ih}_{\mathrm{h}} \\
\text { peak pos. } \\
\left(\mathrm{I}_{\mathrm{h}}+\mathrm{L}\right) \\
{\left[\mathrm{cm}^{-1}\right]}\end{array}$ & $\begin{array}{c}\text { Ice } \mathrm{Ih}_{\mathrm{h}} \\
\text { peak pos. } \\
\left(\mathrm{I}_{\mathrm{h}}+\mathrm{IV}\right) \\
{\left[\mathrm{cm}^{-1}\right]}\end{array}$ & $\begin{array}{c}\text { Ice } \mathrm{Ih}_{\mathrm{h}} \\
\text { peak pos. } \\
\left(\mathrm{I}_{\mathrm{h}}+\mathrm{III}\right) \\
{\left[\mathrm{cm}^{-1}\right]}\end{array}$ & $\begin{array}{c}\text { Ice } \mathrm{lh}_{\mathrm{h}} \\
\text { peak pos. } \\
\left(\mathrm{I}_{\mathrm{h}}+\mathrm{Vap}\right) \\
{\left[\mathrm{cm}^{-1}\right]}\end{array}$ \\
\hline-0.4 & 209.7 & & & 209.5 & 3154.7 & & & $\begin{array}{l}3152.5 \\
3152.0 \\
\end{array}$ \\
\hline-1.9 & 210.1 & & & & 3148.1 & & & 3151.9 \\
\hline-5.8 & 213.6 & & & & 3139.6 & & & \\
\hline-9.7 & $\begin{array}{l}215.4 \\
215.0\end{array}$ & & & 210.5 & 3132.2 & & & $\begin{array}{l}3148.6 \\
3148.8\end{array}$ \\
\hline-13.6 & 217.3 & & & & 3126.1 & & & \\
\hline-17.5 & $\begin{array}{l}218.7 \\
219.0 \\
\end{array}$ & & & 211.7 & 3120.3 & & & $\begin{array}{l}3145.3 \\
3145.3\end{array}$ \\
\hline-19.4 & & & & & $\begin{array}{l}3117.9 \\
3117.6 \\
3117.8\end{array}$ & & & \\
\hline-21.4 & 221.0 & & & & 3114.4 & & & \\
\hline-24.3 & $\begin{array}{l}221.6 \\
221.7\end{array}$ & & 221.1 & 212.7 & $\begin{array}{l}3110.4 \\
3111.0 \\
3111.2\end{array}$ & & 3112.4 & $\begin{array}{l}3141.7 \\
3142.5\end{array}$ \\
\hline-29.2 & $\begin{array}{l}223.5 \\
223.2\end{array}$ & & & & $\begin{array}{l}3104.6 \\
3104.7 \\
3104.5\end{array}$ & & & \\
\hline-32.7 & 224.6 & & & & 3099.9 & & & \\
\hline-33.1 & 225.0 & $\begin{array}{l}224.7 \\
224.7\end{array}$ & & 213.6 & 3100.0 & 3100.2 & & $\begin{array}{l}3138.8 \\
3138.5\end{array}$ \\
\hline-36.0 & 225.3 & $\begin{array}{l}225.0 \\
225.0\end{array}$ & & & & & & \\
\hline-37.9 & 226.0 & & & & & & & \\
\hline-38.9 & 226.3 & $\begin{array}{l}225.5 \\
225.4\end{array}$ & & 213.7 & 3092.8 & $\begin{array}{l}3097.8 \\
3097.3 \\
3097.1 \\
\end{array}$ & & $\begin{array}{l}3135.2 \\
3136.3\end{array}$ \\
\hline-39.9 & & & & & 3091.9 & 3096.5 & & \\
\hline-48.6 & $\begin{array}{l}228.9 \\
229.0 \\
\end{array}$ & $\begin{array}{l}226.5 \\
226.5 \\
\end{array}$ & & 214.9 & $\begin{array}{l}3083.9 \\
3083.9\end{array}$ & $\begin{array}{l}3094.0 \\
3093.5\end{array}$ & & $\begin{array}{l}3132.0 \\
3132.7\end{array}$ \\
\hline-58.4 & $\begin{array}{l}231.6 \\
231.7 \\
231.6\end{array}$ & $\begin{array}{l}227.1 \\
227.0 \\
227.3\end{array}$ & 224.2 & 215.3 & $\begin{array}{l}3074.9 \\
3075.5\end{array}$ & $\begin{array}{l}3090.5 \\
3090.2 \\
3090.5 \\
3090.6\end{array}$ & 3099.4 & $\begin{array}{l}3128.8 \\
3129.6\end{array}$ \\
\hline-68.1 & $\begin{array}{l}233.3 \\
233.6\end{array}$ & $\begin{array}{l}227.8 \\
227.8\end{array}$ & & 216.2 & 3067.6 & $\begin{array}{l}3087.0 \\
3087.4\end{array}$ & & $\begin{array}{l}3126.7 \\
3127.3 \\
\end{array}$ \\
\hline-77.9 & 235.3 & 228.5 & & 216.9 & 3062.0 & 3082.6 & & $\begin{array}{l}3123.9 \\
3124.0\end{array}$ \\
\hline-79.8 & & 229.0 & & & & 3082.4 & & \\
\hline
\end{tabular}

numbers with increasing temperature and towards lower wave numbers with increasing pressure. In contrast, for the (lowfrequency) lattice translational Raman band, the shift of the peak position as a function of $p$ and $T$ is exactly the opposite. The dominant ice $\mathrm{I}_{\mathrm{h}}$ peak of the translational band is at around $220 \mathrm{~cm}^{-1}$. In the high-density inclusion A we observed ice $I_{h}$ in three different phase assemblages: coexisting with liquid water (L), with ice IV, and with ice III. Additionally, ice $I_{h}$ coexists with water vapour (Vap) in the low-density inclusion $B$. Prior to the Raman measurements along the sublimation curve, inclusion $B$ was heated to $-0.1^{\circ} \mathrm{C}$ to promote re-crystallisation of ice $\mathrm{I}_{\mathrm{h}}$. In Fig. 5 the measured ice $\mathrm{I}_{\mathrm{h}}$ peak positions listed in Table 1 are plotted along these four coexistence lines as a function of temperature, both for the lattice translational band (a) and for the $\mathrm{O}-\mathrm{H}$ stretching band (b). The colours of the data points indicate the different coexistence lines (red $=$ ice $I_{h}+L$, orange $=$ ice $I_{h}+$ ice IV, purple $=$ ice $I_{h}+$ ice III, and blue $=$ ice $I_{h}+$ Vap). Replicate measurements at specific temperatures were performed either at the end of a microthermometric cycle 2-4 hours after the initial measurement, or several days later during a new temperature run. The reproducibility of the measurements was good and the data points describe a monotonic (non-linear) trend of the ice $I_{h}$ peak position along the individual coexistence lines without any steps or distinctive kinks. Empirical fits of the data along the ice $I_{h}$ melting and sublimation lines and along the ice $I_{h}+$ ice IV coexistence line (Eq. (1)-(6)) are reported in Table 2. The data fits comply with a series of boundary conditions, 1 . the ice $I_{h}$ 

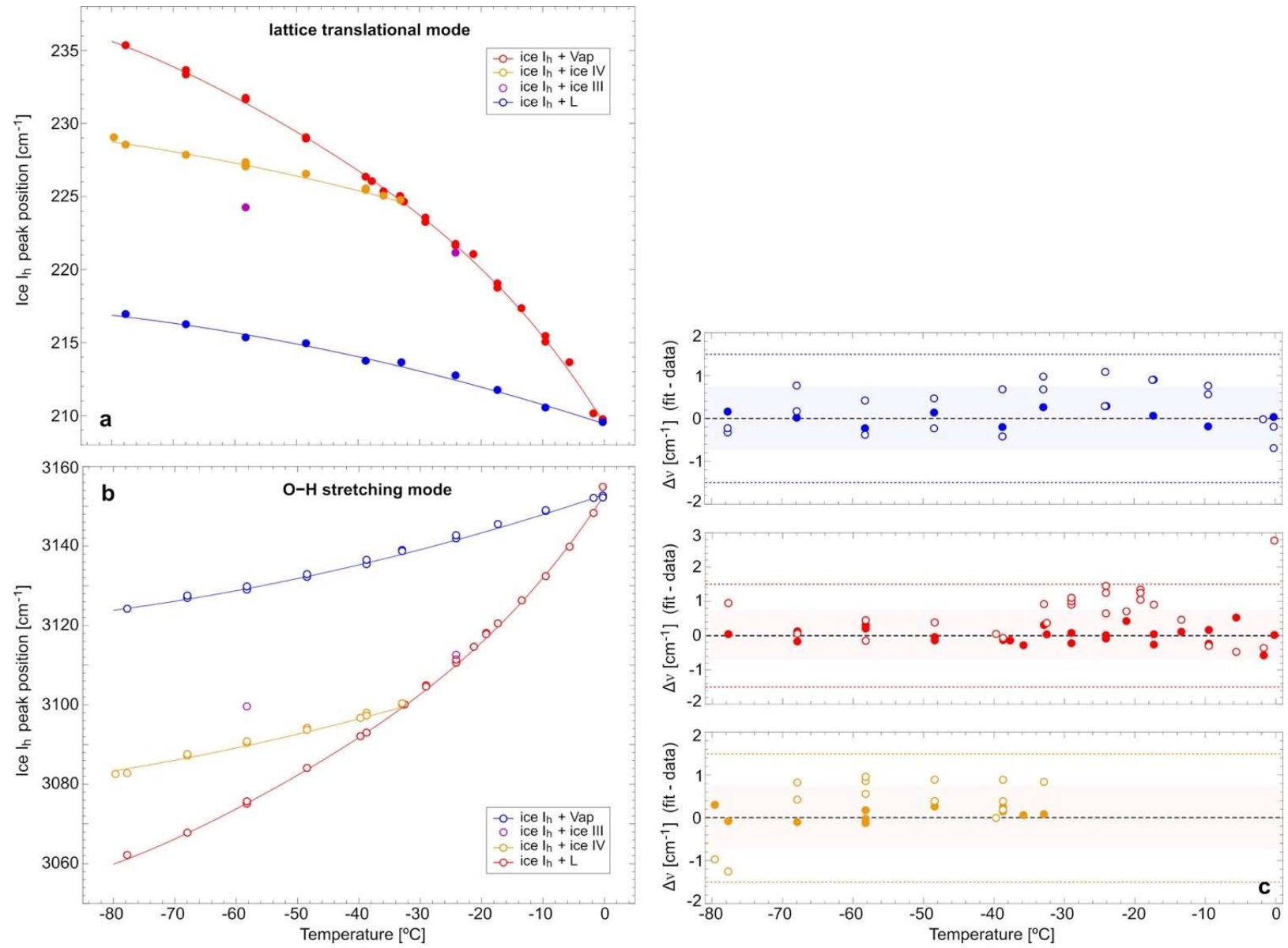

Figure 5: Ice $\mathrm{I}_{\mathrm{h}}$ peak positions as a function of temperature (and pressure). a) lattice translational mode (filled circles) b) O-H stretching mode (open circles). Colors tag the four phases coexisting with ice $\mathrm{I}_{\mathrm{h}}$ : liquid water (red), ice IV (orange), ice III (purple) and water vapour (Vap) (blue). Solid lines are fits to the measured data (see Eq. (1)-(6)). c) Deviation of the data from the corresponding fits. Except for one data point at $-0.4{ }^{\circ} \mathrm{C}$, all measurements are within the estimated precision $\left( \pm 0.75 \mathrm{~cm}{ }^{-1}\right.$ for the lattice translational band (shaded area) and $\pm 1.5 \mathrm{~cm}^{-1}$ for the $\mathrm{O}-\mathrm{H}$ stretching band (horizontal lines).

melting and the sublimation curve intersect at $0.01^{\circ} \mathrm{C}, 2$. the ice $I_{h}$ melting curve and the ice $\mathrm{I}_{\mathrm{h}}$-ice IV coexistence curve intersect at $32.7^{\circ} \mathrm{C}, 3$. the deviation of the fit functions from the measured data points is less than $\pm 1.5 \mathrm{~cm}^{-1}$ for the $\mathrm{O}-\mathrm{H}$ stretching mode and less than $\pm 0.75 \mathrm{~cm}^{-1}$ for the lattice translational mode, and 4 . the fits of the low- and of the high-frequency data eventually yield the same pressures for the ice $I_{h}$ melting curve and the ice $I_{h}$-ice IV coexistence curve, respectively. The deviation of the individual data points from the fits are shown in Fig $5 \mathrm{c}$ with filled symbols representing the low-frequency data and open symbols for the high-frequency data. Except for a single high-frequency data point at $-0.4^{\circ} \mathrm{C}$, the

Table 2: Empirical fits to the $v-T$ data of ice $I_{h}$ along the melting curve (ice $I_{h}+L$ ), the ice $I_{h}$-ice IV coexistence curve (ice $I_{h}+$ ice IV) and the sublimation curve (ice $I_{h}+$ Vap).

\begin{tabular}{|c|c|c|c|}
\hline Binodal & Ice $\ln$ peak position: Lattice translational band & Validity range $\left[{ }^{\circ} \mathrm{C}\right]$ & \\
\hline \multirow[t]{2}{*}{ ice $\ln +\mathrm{L}$} & $v\left[\mathrm{~cm}^{-1}\right]=209.4476-6.826855 \cdot 10^{-1} \mathrm{~T}-9.367985 \cdot 10^{-3} \mathrm{~T}^{2}$ & 0 to -80 & (1) \\
\hline & $-9.510851 \cdot 10^{-5} T^{3}-4.19475 \cdot 10^{-7} T^{4}$ & & \\
\hline ice $\ln +$ ice IV & $v\left[\mathrm{~cm}^{-1}\right]=220.3097-1.4932 \cdot 10^{-1} T-5.483 \cdot 10^{-4} T^{2}$ & -32.7 to -80 & (2) \\
\hline \multirow[t]{2}{*}{ ice $I_{h}+V a p$} & $v\left[\mathrm{~cm}^{-1}\right]=209.44214-1.367092 \cdot 10^{-1} \mathrm{~T}-5.476089 \cdot 10^{-4} \mathrm{~T}^{2}$ & 0 to -80 & (3) \\
\hline & Ice $I_{h}$ peak position: O-H stretching band & & \\
\hline \multirow[t]{2}{*}{ ice $\mathrm{I}_{\mathrm{h}}+\mathrm{L}$} & $v\left[\mathrm{~cm}^{-1}\right]=3152.911+2.381942 T+3.202941 \cdot 10^{-2} T^{2}$ & 0 to -80 & (4) \\
\hline & $+3.243083 \cdot 10^{-4} T 3+1.430337 \cdot 10^{-6} T^{4}$ & & \\
\hline ice $\ln +$ ice IV & $v\left[\mathrm{~cm}^{-1}\right]=3115.885+5.562891 \cdot 10^{-1} \mathrm{~T}+1.95237 \cdot 10^{-3} \mathrm{~T}^{2}$ & -32.7 to -80 & (5) \\
\hline ice $I_{h}+$ Vap & $v\left[\mathrm{~cm}^{-1}\right]=3152.92968+5.201679 \cdot 10^{-1} T+1.9525139 \cdot 10^{-3} T^{2}$ & 0 to -80 & (6) \\
\hline
\end{tabular}


resulting deviations are smaller than the estimated uncertainties. For the ice $I_{h}$-ice III coexistence line we can report only four data points at -24.3 and $-58.4{ }^{\circ} \mathrm{C}$ plus the triple point measurement at $22.0^{\circ} \mathrm{C}$. As previously mentioned, the appearance of ice III was observed for the first time at the very end of our Raman measurements and at the time we did not succeed to re-nucleate ice III after measuring the triple point temperature. Later on, we managed to produce ice III again by chance but using another microthermometric setup that was not coupled to a Raman spectrometer.

Temperature and pressure calibration of the ice $I_{h}$ peak position. Numerical literature values of the temperature- and pressuredependency of the ice $I_{h}$ peak position, $(\partial v / \partial T)_{p=\text { const }}$ and $(\partial v / \partial p)_{T=}$ const., respectively, are sparse and in poor agreement. ${ }^{23,27,28}$ For this reason, we re-calibrated the shift of the Raman peak position of ice $\mathrm{Ih}$ as a function of temperature and pressure for both the $\mathrm{O}-\mathrm{H}$ stretching and the lattice translational band. The results are shown in Table 3.

The temperature-dependent shift $(\partial v / \partial T)_{p=0}$ was determined along the water sublimation curve using the low-density pure water inclusion B mentioned above. The data points (blue dots) shown in Fig 5 indicate a slightly non-linear trend of the ice $I_{h}$ peak position. This non-linearity is in agreement with previous experimental data compiled by Shi et al. ${ }^{29}$ (see their Fig. 7). The slope $(\partial v / \partial T)_{p=0}$ of the ice $I_{h}$ peak position is given by equation (7) for the lattice translational band and by equation (10) for the $\mathrm{O}-\mathrm{H}$ stretching band.
The pressure-dependent shift of the ice $I_{h}$ peak position, in contrast, could not be determined from direct measurements at constant temperature. Instead we used inclusion $A$ to record the Raman peak positions $v_{p, T}$ along the ice $\ln _{\mathrm{h}}$ melting curve between 0 and $-22^{\circ} \mathrm{C}$ (see Fig. 5) and subtracted the temperature related $v_{T}$ portion of the shift using Eq. (7) and Eq. (10), respectively. The resulting $\Delta v$ value corresponds to the pressure-dependent portion $v_{p}$ of the Raman shift. Since $\Delta v=v_{p}=v_{p, T}-v_{T}$ we obtain positive $v_{p}$ values for the lattice translational mode and negative $v_{p}$ values for the $\mathrm{O}-$ $\mathrm{H}$ stretching mode. Using then the expression of Wagner et al. ${ }^{30}$ for the $p$ - $T$ trend of the ice $I_{h}$ melting curve (a polynomial fit to experimental data) we derived the pressure-dependent Raman shift $(\partial v / \partial p)_{T=\text { const }}$ of ice $\mathrm{I}_{\mathrm{h}}$ for the lattice translational and for the $\mathrm{O}-\mathrm{H}$ stretching mode. Although the slope $(\partial v / \partial p)_{T=\text { const }}$ was found to be nearly linear in the range between 0 and $208 \mathrm{MPa}$, we decided for a non-linear fit of the $p$ - $v_{p}$ data, which eventually results in higher pressures when extrapolated beyond $208 \mathrm{MPa}$. The triple point pressure of $611.657 \mathrm{~Pa}$ at $\Delta v=0$ was set as a boundary condition for the data fit. The slopes of the resulting $p$ - $v_{p}$ curves are given by equations (8) and (11) for the lattice translational band and for the $\mathrm{O}-\mathrm{H}$ stretching band, respectively. The validity range of equations (8) and (11) is from 0 to $208 \mathrm{MPa}$ but in the present study we extrapolated them up to $460 \mathrm{MPa}$. Since $v_{p}$ is the measured variable in our experiments we used equation (9) and (12) to calculate the ice pressure in the inclusions.

Table 3: Calibration of the temperature- and pressure-dependent shift of the Raman peak position of ice $\mathrm{l}$ for the lattice translational and the $\mathrm{O}-\mathrm{H}$ stretching band. Note, the slopes $(\partial v / \partial T)_{p=0}$ and $(\partial v / \partial p)_{T=\text { const }}$ are non-linear.

\begin{tabular}{|c|c|c|c|}
\hline & Ice In peak position: Lattice translational band & Validity range & \\
\hline$p=$ const. & $(\partial v / \partial T)_{p=0}=-0.13671-5.4761 \cdot 10^{-4} T$ & 0 to $-80 \stackrel{\circ}{C}$ & (7) \\
\hline$T=$ const. & $(\partial v / \partial p)_{T=\text { const. }}=0.0430-6.108 \cdot 10^{-6} \cdot p$ & 0 to $208 \mathrm{MPa}$ & (8) \\
\hline \multirow[t]{2}{*}{$p\left(v_{p}\right)$} & $p=6.2681 \cdot 10^{-4}+23.1338 \cdot v_{p}+9.295 \cdot 10^{-2} \cdot v_{p}^{2}$ & 0 to $208 \mathrm{MPa}$ & (9) \\
\hline & Ice $\ln$ peak position: $\mathrm{O}-\mathrm{H}$ stretching band & & \\
\hline$p=$ const. & $(\partial v / \partial T)_{p=0}=+0.520168+1.9525 \cdot 10^{-3} T$ & 0 to $-80 \stackrel{\circ}{C}$ & (10) \\
\hline$T=$ const. & $(\partial v / \partial p)_{T=\text { const. }}=-0.1462+1.963 \cdot 10^{-5} \cdot p$ & 0 to $208 \mathrm{MPa}$ & (11) \\
\hline$p\left(v_{p}\right)$ & $p=6.1659 \cdot 10^{-4}-6.78448 \cdot v_{p}+7.99 \cdot 10^{-3} \cdot v_{p}^{2}$ & 0 to $208 \mathrm{MPa}$ & (12) \\
\hline
\end{tabular}

\section{The $p-T$ phase diagram}

Based on the fits of the $v-T$ data shown in Fig. 5 we calculated the $p$ - $T$ trend of the melting curve (ice $\mathrm{I}_{\mathrm{h}}+\mathrm{L}$ ) between 0 and $-80^{\circ} \mathrm{C}$ and of the ice $\mathrm{Ih}_{\mathrm{h}}$-ice IV coexistence line between -32.7 and $-80^{\circ} \mathrm{C}$, using the temperature and pressure calibrations of the ice Ih Raman shift described above. Equations (13) and (14) reported in Table 4 describe the resulting $p-T$ curves that are shown in the phase diagram in Fig. 6. In addition, the diagram displays the approximate trend of the ice $I_{h}$-ice III coexistence curve, based on the four data points obtained at -58.4 and $-24.3^{\circ} \mathrm{C}$, and on the triple point temperature measured at $-22.0^{\circ} \mathrm{C}$. Data points calculated from the measured low-frequency (filled circles) and high-frequency (open circles) peak position of ice $\mathrm{l}$ are shown in the respective colours. The deviation $\Delta p$ of the individual data points from the calculated curves is shown in Fig. 7. The $\Delta p$ plots indicate a precision of the pressure determination of about $\pm 10 \mathrm{MPa}$ for both the low- and the high-frequency data.

Figure 6 additionally displays the stability fields of liquid water, ice Ih, ice II (grey shaded area), ice III, and ice V (ref. ${ }^{4}$ ) as a reference framework to contrast our results with. The 


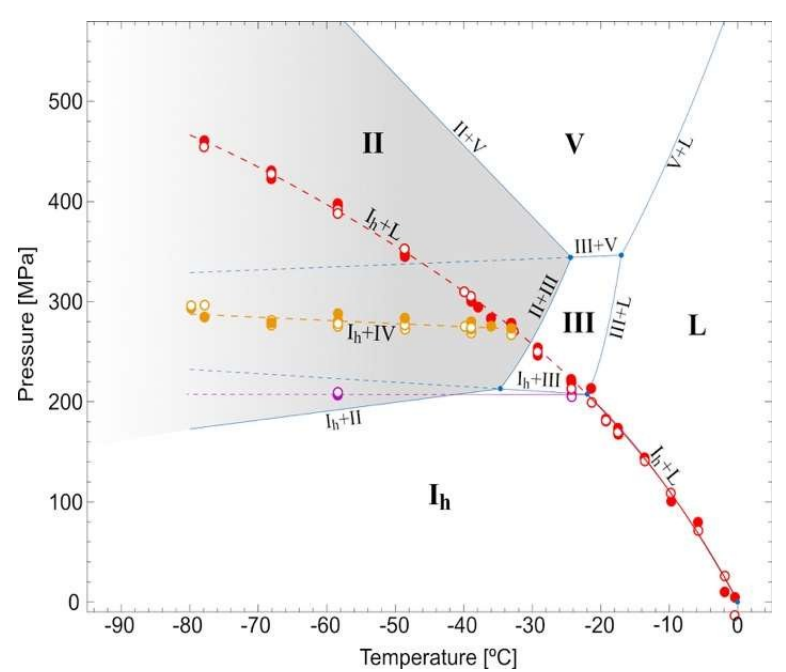

Figure 6: Detail of the $p-T$ phase diagram of water showing the stability fields of liquid water (L), ice $\mathrm{I}$, ice II, ice III and ice V and the respective phase boundaries (blue) based on experimental data from Bridgman 4 . Solid lines denote stable, dashed lines metastable phase equilibria. The ice $I_{h}$ melting curve (red) and the ice $I_{h}$-ice IV coexistence curve (orange) were calculated from the fits of the measured ice $I_{h}$ peak positions (Eq. (1)-(6)) using Eq. (9) and (12). Filled circles denote data points derived from low-frequency, open circles from high-frequency Raman measurements. The approximate trend of the $\mathrm{I}_{\mathrm{h}}$-ice III equilibrium line is shown in purple.

respective solid-liquid and solid-solid binodals are shown in blue with solid lines for stable and dashed lines for metastable phase equilibria. Bridgman was probably the first who reported on the "prolongation of the I-L curve" below $22{ }^{\circ} \mathrm{C}$ (see ref. ${ }^{4}$, p. 478). However, his ice $\mathrm{l}$ melting curve terminates at the ice $\mathrm{Ih}_{\mathrm{h}}$-ice III-liquid triple point. In the present study, we could trace the melting curve into the lowtemperature metastable region down to $-80^{\circ} \mathrm{C}$ (red dashed line). Below $-22.0^{\circ} \mathrm{C}$ the two phases, ice $\mathrm{Ih}$ and liquid water, become metastable first, with respect to ice III and then, below $-30{ }^{\circ} \mathrm{C}$, with respect to ice II. At $-80^{\circ} \mathrm{C}$ and $466 \mathrm{MPa}$, the super-cooled ice $\ln$ melting curve eventually terminates due to the nucleation of either ice IV or ice III. The nucleation of ice IV results in a pressure drop of approximately 180 $\mathrm{MPa}$, while the pressure drop associated with the nucleation of ice III is about $260 \mathrm{MPa}$.

Table 4: Empirical equations describing the $p$ - $T$ trend of the ice $\ln$ melting curve and the ice $\mathrm{I}_{\mathrm{h}}$-ice IV coexistence curve shown in Fig. 6.

\begin{tabular}{lcc} 
Binodal & \multicolumn{1}{c}{ Equation: $p[\mathrm{MPa}], T\left[{ }^{\circ} \mathrm{C}\right]$} & Validity range \\
\hline ice $\mathrm{I}_{\mathrm{h}} \mathrm{L}$ & $p=1.28108604 \cdot 10^{-1}-12.74778 \cdot T-1.915212 \cdot 10^{-1} \cdot T^{2}$ & 0 to $-80^{\circ} \mathrm{C}$ \\
& $-2.01501 \cdot 10^{-3} \cdot T^{3}-8.775 \cdot 10^{-6} \cdot T^{4}$ & $(13)$ \\
ice $\mathrm{I}_{\mathrm{h}}+\mathrm{ice} I V$ & $p=262.294-0.316 \cdot T$ & -32.7 to $-80{ }^{\circ} \mathrm{C}$
\end{tabular}

the $v$ - $T$ data exhibits a linear $p$ - $T$ trend with a slightly negative slope. Both phases are metastable with respect to ice II and their coexistence terminates at the intersection with the metastable ice $I_{h}$ melting curve, forming a triple point of three metastable phases (ice $\mathrm{Ih}$, ice IV and L) at -32.7 ${ }^{\circ} \mathrm{C}$ and $273 \mathrm{MPa}$.

The $p-T$ trend of the ice $I_{h}$-ice III coexistence curve, finally, is not well constrained by our data. The two data points at $58.4{ }^{\circ} \mathrm{C}$ are located in the ice II stability field, and thus represent a metastable phase equilibrium, while the data points at $-24.3^{\circ} \mathrm{C}$ represent the stable phase equilibrium. The ice $\mathrm{I}_{\mathrm{h}}$-ice III-L triple point was measured at $-22.0^{\circ} \mathrm{C}$ and the pressure was determined at $207 \mathrm{MPa}$. While the triple point is in agreement with the measurements reported by Bridgman ${ }^{4}$, we note that our data points at $-58.4{ }^{\circ} \mathrm{C}$ plot clearly below Bridgman's ice Ih-ice III coexistence curve. 


\section{Discussion}

\section{Comparison with literature data.}

In order to draw a more complete picture of the metastable phase relations observed in this study and to compare our data, we have complemented the phase diagram with available data from the literature (Fig. 8a). Experimental data of the low-temperature metastable extension of the ice $\mathrm{I}_{\mathrm{h}}$ melting curve have previously been measured by Mishima ${ }^{9,31}$ using a water-emulsion technique. The scatter of these data (yellow dots) is somewhat larger than that of our data and the overall trend of Mishima's measurements indicates a slightly different curvature of the ice $I_{h}$ melting line, leading to higher pressures in the metastable region and slightly lower pressures in the stable region above $-22{ }^{\circ} \mathrm{C}$. Considering experimental uncertainties of the two data sets, our results (red curve) are in acceptable agreement with Mishima's $p-T$ data of the super-cooled ice $\mathrm{I}_{\mathrm{h}}$ melting curve. In addition to the experimental data of Mishima, the diagram displays a calculated ice $I_{h}$ melting curve derived by combination of the Equation of State (EOS) of ice $I_{h}$ ${ }^{32}$ and the EoS for super-cooled water ${ }^{20}$. This melting line (brown) again is slightly more curved in the metastable region running close to the minimum melting pressures determined by Mishima, and hence deviates only slightly from the melting curve obtained in this study. The third ice $I_{h}$ melting curve shown in the diagram (dark grey) was derived by extrapolation of the expression of Wagner et al. ${ }^{30}$. Below $-22{ }^{\circ} \mathrm{C}$ this curve deviates progressively from the two other ice melting lines and eventually exceeds the maximum ice melting pressures measured by Mishima.

In order to explain the nucleation of either ice IV or ice III at $-80^{\circ} \mathrm{C}$ Fig. 8a displays experimental data (blue dots) of the homogeneous nucleation limit $T_{\mathrm{H}} \cdot{ }^{10,33}$ The corresponding $T_{\mathrm{H}}$ curves were calculated using data fits of Holten et al. ${ }^{20}$ (Eq. A1 and A2) that include additional experimental data in the range between 500 and $1500 \mathrm{MPa} .{ }^{34}$ The homogeneous nucleation limit exhibits a break point at about $-92{ }^{\circ} \mathrm{C}$ and $200 \mathrm{MPa}$. At low pressures the negatively sloped $T_{\mathrm{H}}$ curve is associated with the nucleation of ice $\mathrm{I}_{\mathrm{h}}$, whereas at high pressures the $T_{H}$ curve has a positive slope and is associated with the nucleation of high-pressure ice polymorphs like ice III and ice IV. The intersection of the high-pressure branch of the $T_{\mathrm{H}}$ curve with our ice $I_{h}$ melting curve (red) is at $-78^{\circ} \mathrm{C}$. This is only two degrees higher than the nucleation temperature actually measured in this study. Our data thus suggest a slightly steeper slope of the $T_{\mathrm{H}}$ line. At this point we call the reader's attention to the fact that Mishima's data9,31 indicate a continuation of the ice $l_{\mathrm{h}}$ melting curve at temperatures below the homogeneous nucleation limit. The reason is that Mishima observed in his experiments the compression-induced melting of ice $\mathrm{I}_{\mathrm{h}}$, starting with emulsified water droplets of 1-10 $\mu \mathrm{m}$ diameter, freezing them to ice $I_{h}$ at low pressure and finally increasing pressure at constant temperature until the exothermic melting transition was recorded. Due to the small size of the droplets in the emulsion, the nucleation of
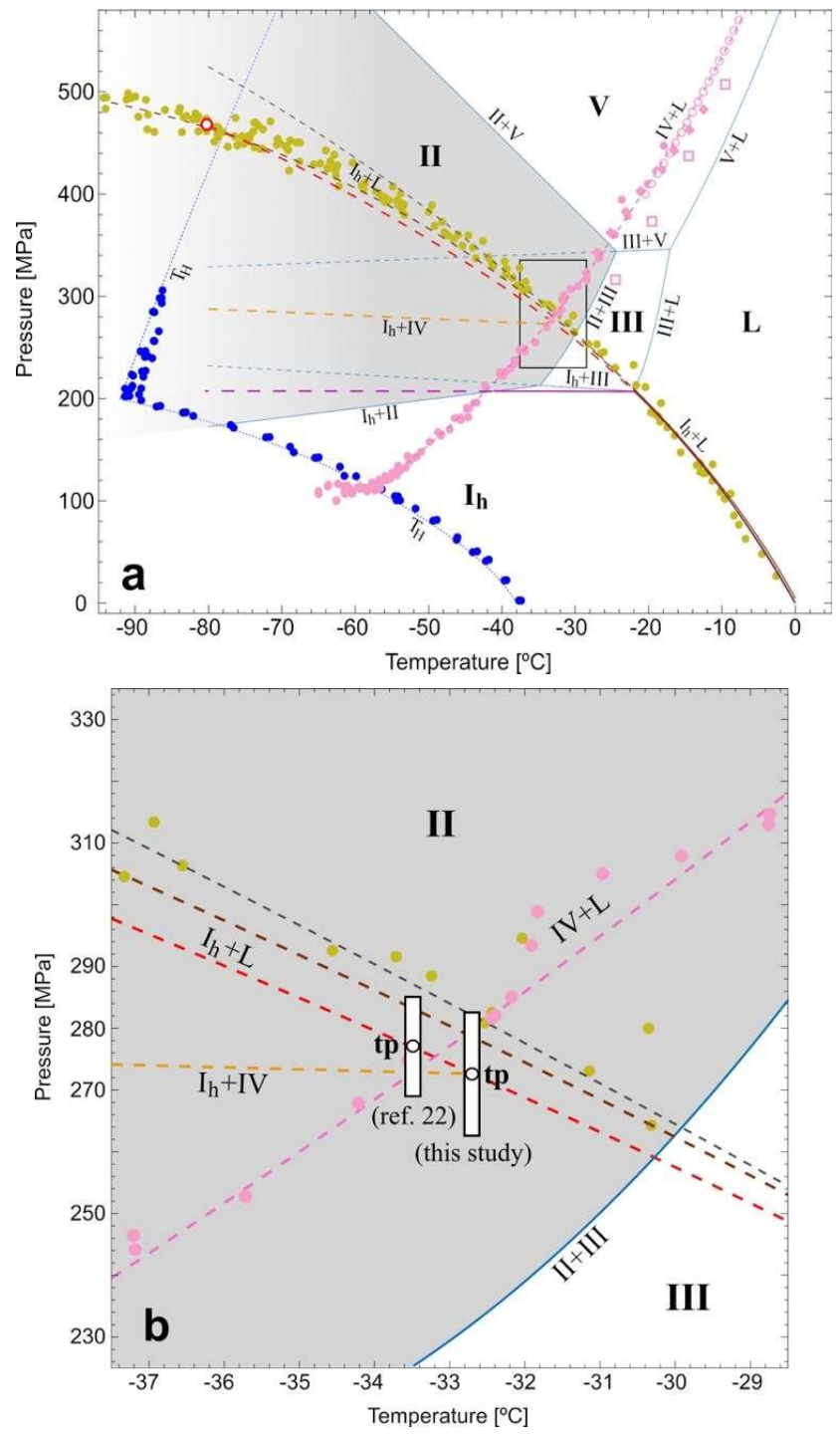

Figure 8: a) Detail of the $p$ - $T$ phase diagram of water like Fig. 6 but featuring additional experimental data from the literature: ice $\mathrm{ln}$ melting pressures (yellow dots) $)^{9,31}$, ice IV melting pressures represented by pink symbols (diamonds ${ }^{5}$, open circles $^{35}$, open squares ${ }^{7}, \operatorname{dots}^{31}$ ), and $p-T$ data of the homogeneous nucleation limit $T_{\mathrm{H}}$ (blue $)^{10,33}$. Three different representations of the ice $I_{h}$ melting curve are shown based on: 1 . the empirical expression of Wagner et al..$^{30}$ extrapolated below $-22^{\circ} \mathrm{C}$ (dark grey line), 2. the combination of the EoS for ice $\mathrm{Ih}^{32}$ and the EoS for super-cooled liquid wate ${ }^{20}$ (brown line) and 3 . the peak positions of the ice $\mathrm{lh}$ Raman bands (red; this study). The ice $\mathrm{I}_{\mathrm{h}}$-ice IV equilibrium curve is shown in orange. See text for further details. b) Enlarged detail of the marked area in a) showing the positions of the triple point (tp) proposed in ref. ${ }^{22}$ and in this study (white bars indicate the stated uncertainties of $p$ and $T$ ). Note that the three binodals (ice $I_{h}+L$, ice $I_{h}+$ ice IV and ice IV $+L$ ) do not intersect in a single point but they confine the potential position of the $\mathrm{h}$-ice IV-liquid triple point.

secondary ice phases is kinetically suppressed, ${ }^{34}$ which explains why the liquid produced by ice melting does not instantaneously freeze to a high-pressure ice phase. In case of the ice IV melting line, also shown in Fig. 8a, melting was induced by decompression of ice IV at constant temperature. And again, the melting curve seems to continue across the $T_{H}$ curve. In this case, however, it is 
not a continuation of the ice IV melting curve, as indicated by the clear change of the slope close to $T_{H}$ but, in fact, the data points below $T_{\mathrm{H}}$ are associated with an "ice IV-to-ice $\mathrm{I}_{\mathrm{h}}$ transition" (cf. ref. ${ }^{31}$ ) that should not be confused with an ice IV-ice $I_{h}$ equilibrium. The coexistence of ice $\mathrm{I}_{\mathrm{h}}$ and ice IV has previously been observed by Chou and Haselton ${ }^{22}$ in a hydrothermal diamond-anvil cell. In their experiments ice IV formed together with ice $I_{h}$ by isochoric cooling of high-density water samples ( 1161 to $1249 \mathrm{~kg} / \mathrm{m}^{3}$ ). However, since the focus of their study was on the determination of the ice IV melting curve at high pressures $(710-1200 \mathrm{MPa})$ they did not measure any $p$ - $T$ data along the ice $I_{h}$-ice IV coexistence line, except for the metastable ice $\mathrm{I}_{\mathrm{h}}$-ice IV-liquid triple point that was determined at $-33.5 \pm 0.1^{\circ} \mathrm{C}$ and $277 \pm 8 \mathrm{MPa}$. Because of the higher densities of their water samples Chou and Haselton observed the melting of ice $I_{h}$ at the triple point (ice IV + Ice $I_{h} \rightarrow$ ice IV $+L$ ) and consequently their samples evolved along the ice IV melting curve upon further heating and not along the ice $I_{h}$ melting line as in the present study. The triple point temperature determined by Chou and Haselton is about $0.8^{\circ} \mathrm{C}$ lower than the value measured in this study $\left(-32.7 \pm 0.1^{\circ} \mathrm{C}\right)$ whereas the triple point pressures coincide within experimental uncertainties. We note that the deviation of the triple point temperatures is significantly larger than the stated temperature accuracies $\left( \pm 0.1^{\circ} \mathrm{C}\right)$ of the two studies. Future remeasurements of this triple point transition might resolve this discrepancy.

The present study provides new experimental $p$ - $T$ data of the ice $I_{h}$ melting curve (red) and of the ice $I_{h}$-ice IV coexistence curve (orange) but not of the ice IV melting curve, the third binodal that intersects the metastable ice $\mathrm{I}_{\mathrm{h}}$-ice IV-liquid triple point. To complete the picture of the triple point, Fig. 8a displays experimental data of the ice IV melting curve (pink symbols) $5,7,31,34,35$. Since the measurements of Nishibata $^{7}$ (open squares) plot systematically below the other data points they were excluded from the data fit (pink dashed line). The resulting ice IV melting curve passes between the proposed triple points (ref. ${ }^{22}$, this study) as illustrated in an enlarged view in Fig. 8b. Its position, passing close to the triple point determined from our measurements provides clear evidence that the ice phase formed at $-80^{\circ} \mathrm{C}$ is in fact ice IV, and thus, confirms the rather vague identification of ice IV based on the Raman spectra. Considering the precision and the accuracy of the individual experimental data sets, it is not surprising that the three binodals do not intersect in a single $p-T$ point but rather confine the potential position of the metastable ice $I_{h}$-ice IV-liquid triple point in $p$ - $T$ space. These findings suggest that the coexistence of ice $I_{h}$ and ice IV expands along a thermodynamic, though metastable, equilibrium line.

\section{Implications for fluid inclusion studies}

Finally, we come back to the questions that initially motivated us to conduct the present study: our results have clearly demonstrated that the ice phase present in the inclusion after nucleation is ice $I_{h}$ even when pressure increases into the ice II stability field. The lowtemperature metastable extension of the ice $\mathrm{I}_{\mathrm{h}}$-liquid binodal furthermore implies that the maximum pressure in the inclusion cannot exceed the melting curve. This in turn explains why irreversible volume changes do not increase with increasing bulk water densities of the inclusions. Preliminary microthermometric experiments using a synthetic fluid inclusion with a density $\varrho$ of 995 $\mathrm{kg} / \mathrm{m}^{3}$, which is higher than that of inclusion $A$, shows larger $\mathrm{L} /$ ice $\mathrm{I}_{\mathrm{h}}$ and ice IV/ ice $I_{h}$ volume ratios, while $T_{n} I V$ as well as the triple point temperature again were measured at $-80^{\circ} \mathrm{C}$ and $-32.7^{\circ} \mathrm{C}$, respectively. This is further proof that the pressure in the inclusion is controlled by metastable ice $\mathrm{I}_{\mathrm{h}}$-liquid and ice $\mathrm{I}_{\mathrm{h}}$-ice IV phase equilibria.

Our results also show that the quartz crystal hosting the fluid inclusions can withstand internal pressures of up to $466 \mathrm{MPa}$ as well as abrupt pressure increases of $315 \mathrm{MPa}$ upon nucleation of ice $\mathrm{I}_{\mathrm{h}}$ without experiencing significant irreversible volume changes due to plastic and/or brittle deformation. For inclusion $A$ the resulting volume increase was found to be below $0.02 \%$, deduced from the increase of the liquid-vapour homogenisation temperature $\left(T_{h}\right)$ from $56.8^{\circ} \mathrm{C}$ (initial value) to $57.1^{\circ} \mathrm{C}$ (measured after several freezing/melting cycles). However, we need to bear in mind that inclusion A was rather small $\left(120 \mu^{3}\right)$ and that the extent of overpressure an inclusion can withstand decreases with increasing size, which has been demonstrated by high-temperature decrepitation experiments (see Roedder ${ }^{36}$, p. 70-72).

\section{Conclusions}

The present study provides a wealth of new experimental data related to the low-temperature phase diagram of water. On the one hand, our results confirm, though with slight deviations, the previous experimental data of Mishima ${ }^{9,31}$ concerning the metastable extension of the ice $I_{h}$ melting curve below the ice $I_{h}$-ice III-liquid triple point. On the other hand, our data describe the $p-T$ trend of a metastable ice $I_{h}$ - ice IV equilibrium curve that terminates in a metastable ice $I_{h}$-ice IV-liquid triple point, previously determined by Chou and Haselton ${ }^{22}$ at a slightly lower temperature compared to the present study. This triple point interlinks the three metastable equilibrium curves: ice $I_{h}+$ ice IV, ice $I_{h}+$ liquid and ice IV + liquid. With regard to the ice $I_{h}$-ice III equilibrium curve, however, further measurements are needed to confirm or disprove the apparent deviation from Bridgman's data. ${ }^{4}$ And last but not least, the present study proposes new, non-linear calibrations of the temperature- and pressure-dependent shift of the ice $\mathrm{I}_{\mathrm{h}}$ Raman bands for the lattice translational and for the $\mathrm{O}-\mathrm{H}$ stretching mode. Although our study has demonstrated that synthetic fluid inclusions can be employed for investigations of solid-liquid and solid-solid phase equilibria in the water phase diagram, further potential applications in this field are rather limited due to the isochoric nature of the experiments, in which the pressure is not an independent variable. A potential example for further applications could be the pressure determination along the super-heated ice $I_{h}$ 
melting curve. This, however, requires an extrapolation of the calibration curves of the ice $I_{h}$ Raman shift to positive temperatures and negative pressures (tensile stress).

More than one century after Bridgman's pioneering work, our knowledge of the water/ice phase diagram, particularly with respect to metastable phase equilibria, is still incomplete and the amount of available experimental data is moderate. New experimental studies are needed to confirm or improve the existing data, and potentially disclose new features of this enormously rich phase diagram of solid water.

\section{List of symbols}

$p \quad$ pressure $(\mathrm{MPa})$

$T$ temperature $\left({ }^{\circ} \mathrm{C}\right)$

$T_{h} \quad$ liquid-vapour homogenisation temperature

$T_{h r} \quad$ retrograde liquid-vapour homogenisation temperature

$T_{\mathrm{H}} \quad$ (temperature of the) homogeneous nucleation limit

$T_{n} \quad$ nucleation temperature of ice $\mathrm{I}_{\mathrm{h}}$, III or IV

$T_{m} \quad$ melting temperature of ice $I_{h}$, III or IV

$v \quad$ Raman shift $\left(\mathrm{cm}^{-1}\right)$

$v_{T} \quad$ temperature-dependent Raman shift $\left(\mathrm{cm}^{-1}\right)$ at $p=$ const.

$v_{p} \quad$ pressure-dependent Raman shift $\left(\mathrm{cm}^{-1}\right)$ at $T=$ const.

$\varrho \quad \operatorname{density~}\left(\mathrm{kg} / \mathrm{m}^{3}\right)$

\section{Conflicts of interest}

There are no conflicts to declare.

\section{Acknowledgements}

The authors thank Osamu Mishima for providing us with numerical data of the ice $I_{h}$ and ice IV melting curves. We also thank Max Wilke for producing the high-density fluid inclusion samples used in this study and Sevasti Modestou for proofreading the manuscript. This work has received support from the French Agency for Research (Agence Nationale de la Recherche, ANR) through the Equipex Planex ANR-11-EQPX-36 and the labex Voltaire ANR-10LABX-100-01.

\section{References}

1 V.F. Petrenko and R.W. Whitworth, Physics of ice, Oxford University Press, 1999.

2 T. Bartels-Rausch, V. Bergeron, J.H.E. Cartwright, R. Escribano, J.L. Finney, H. Grothe, P.J. Gutiérrez, J. Haapala, W.F. Kuhs, J.B.C. Pettersson, S.D. Price, C.I. Sainz-Díaz, D.J. Stokes, G. Strazzulla, E.S. Thomson, H. Trinks and N. UrasAytemiz, Rev. Mod. Phys., 2012, 84, 885-944.

3 C.G. Salzmann, J. Chem. Phys., 2019, 150, 060901 1-9

4 P.W. Bridgman, Proc. Am. Acad. Arts and Sci., 1912, XLVII, 13, 441-558

5 L.F. Evans, J. Appl. Phys., 1967, 38, 4930-4932.

$6 \quad$ E. Roedder, Science, 1967, 155, 1413-1417.
K. Nishibata, Jpn. J. Appl. Phys., 1972, 11, 1701-1708.

S.J. Henderson, and R.J. Speedy, J. Phys. Chem., 1987, 91, 3069-3072

O. Mishima, Nature, 1996, 384, 556-559.

H. Kanno, R.J. Speedy, C.A. Angell, Science, 1975, 189, 4206, 880-881.

O. Mishima, L.D. Calvert, E. Whalley, Nature, 1984, 310, $393-$ 395.

J.L. Green, D. J. Durben, G. H. Wolf, C. A. Angell, Science, 1990, 249, 649-652.

Q. Zheng, D.J. Durben, G.H. Wolf, C.A. Angell, Science, 1991, 254, 829-832.

K.I. Shmulovich, L. Mercury, R. Thiéry, C. Ramboz, M. El Mekki, Geochim. Cosmochim. Acta, 2009, 73, 2457-2470.

M.E.M. Azouzi, C. Ramboz, J.-F. Lenain, F. Caupin, Nat. Phys., 2013, 9, 38-41.

C. Qiu, Y. Krüger, M. Wilke, D. Marti, J. Rička, M. Frenz, Phys. Chem. Chem. Phys., 2016, 18, 28227-28241.

7 Y. Krüger, P. Stoller, J. Rička, M. Frenz, 2007. Eur. J. Mineral., 2007, 19, 693-706.

8 D. Marti, Y. Krüger, D. Fleitmann, M. Frenz, J. Rička, Fluid Phase Equilib., 2012, 314, 13-21.

D. Marti, Y. Krüger, M. Frenz, ECROFI XX Abstracts, 2009, 163-164

V. Holten, J.V. Sengers, M.A. Anisimov, J. Phys.Chem. Ref. Data, 2014, 43, 1-23

W. Thomson, Philos. Mag., 1871, 42, 448.

I.-M. Chou, H.T. Haselton, Rev. High Pressure Sci. Technol., 1998, 7, 1132-1134

B. Minceva-Sukarova, W.F. Sherman, G.R. Wilkinson, J. Phys. C: Solid state Phys., 1984, 17, 5833-5850.

C.G. Salzmann, I. Kohl, T. Loerting, E. Mayer, A. Hallbrucker, J. Phys. Chem. B, 2003, 107, 2802-2807.

M.J. Taylor, E. Whalley, J. Chem. Phys.,1964, 40, 1660-1664. 1654 .

T.C. Sivakumar, H.A.M. Chew, G.P. Johari, 1978. Nature, 1978, 275, 524-525.

8 G.E. Slark, A.K. Garg, W.F. Sherman, G.R. Wilkinson, J. Mol. Struct., 1984, 115, 161-164.

L. Shi, S.M. Gruenbaum, J.L. Skinner, J. Phys. Chem. B, 2012, 116, 13821-13830.

W. Wagner, T. Riethmann, R. Feistel, A.H. Harvey, J. Phys. Chem. Ref. Data, 2011, 40, 043103 1-11.

O. Mishima, 2011. J. Phys.Chem. B, 2001, 115, 14064-14067. R. Feistel, W. Wagner, J. Phys. Chem. Ref. Data, 2006, 35, 1021-1047.

H. Kanno, K. Miyata, Chem. Phys. Lett., 2006, 422, 507-512. O. Mishima, H.E. Stanley, Nature, 1998, 392, 164-168. H. Engelhardt, E. Whalley, J. Chem. Phys., 1972, 56, 6, 26782684.

E. Roedder, Review in Mineralogy, 1984, 12, Mineralogical Society of America, Chelsea, Michigan. 